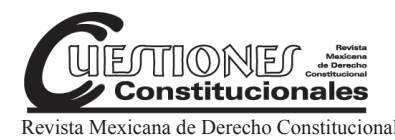

Núm. 37, julio-diciembre 2017

\title{
APUNTES DE ULTRAMAR A PROPÓSITO DEL DEBATE SOBRE LAS PERSPECTIVAS DE REFORMA DE LA CONSTITUCIÓN POLÍTICA DE LOS ESTADOS UNIDOS MEXICANOS
}

Antonio López CASTILlO*

I. Antes de apuntar al detalle, me permitiré algunas referencias previas de carácter doctrinal que siempre conviene tener presentes en un debate sobre la reforma constitucional. A propósito, lo primero que se ha de intentar es diferenciar lo más netamente posible los conceptos de Constitución y de orden constitucional, y distinguir entre constituir y constitucionalizar. ${ }^{1}$

De una Constitución, como (sintética) expresión y forma del poder, ${ }^{2}$ ciertamente no puede esperarse que responda siempre a un modelo estandarizado único e indiferenciado, pero no es menos cierto que a ese nomen iuris no puede ligarse cualquier textura o contenido normativo, a no ser que se incurra en grosero y burdo nominalismo.

En consecuencia, la Constitución no puede contener el orden constitucional en su conjunto. Y - dicho sea sin perjuicio de variantes históricas y de posibles procesos de agregación normativa - ni siquiera puede pretender fungir como una especie de código de leyes constitucionales.

Por otra parte, en el proceso de constitucionalización se ha de atender tanto al proceso de formalización normativa como al sustrato constitutivo. Dicho sea esto en un doble sentido: estructural y funcional.

\footnotetext{
* Profesor-doctor en la Universidad Autónoma de Madrid.

1 Al respecto, se remite aquí a la contribución de López Castillo, Antonio, “La Unión Europea «en Constitución...»", en idem/e.a., Constitución española y Constitución europea, foro 1, Madrid, CEPC, 2005, pp. 11-49.

2 A propósito de la categoría, Rubio Llorente, Francisco, La forma del poder, 3a. ed., Madrid, CEPC, 2012.
} 
Esta revista forma parte del acervo de la Biblioteca Jurídica Virtual del Instituto de Investigaciones Jurídicas de la UNAM

En un sentido estructural, se ha de constitucionalizar sin desajustar la constitutiva dualidad de la legitimación en el Estado constitucional, lo cual requiere de una doble articulación de efectiva participación democrática y control, en una relación de directa proporcionalidad con la compleja urdimbre de la sociedad y con la paulatina diversificación funcional de las potestades públicas, que resultan características (por más que se hallen en un diverso grado de articulación) del contemporáneo Estado constitucional.

$Y$, en un sentido funcional, mediante observancia de exigencias de congruencia y eficiencia, sin las cuales apenas resulta imaginable la articulación de los poderes y el desempeño articulado, ordenado y especializado, de las funciones públicas, que está en la base del Estado (constitucional) de derecho.

II. A propósito ya de la concreta (y reciente) evolución-reforma de la Constitución mexicana, tras una primera aproximación que, por fuerza, ha de ser muy cautelosa, puede apreciarse una relativa necesidad de acomodo a esas exigencias estructurales y sustantivas de congruencia y eficiencia. Veamos esto mediante dos referencias de extensiva regulación constitucional, por concreción o por remisión.

A propósito de la regulación por concreción, puede subrayarse el criterio de que una inserción de artículos extensos no corresponde con los estándares contrastados de lo que sea una Constitución, pues, apenas podría eludirse incurrir en un detalle más propio de la ley, cuando no del reglamento. En este tipo de supuesto, formalmente aparecerán insertos en el texto de la Constitución, elementos secundarios, normativamente complementarios y políticamente coyunturales.

Por lo que hace a la modalidad de extensiva inclusión por remisión, propia de las cláusulas de apertura, características del constitucionalismo de la globalización, bien puede mencionarse aquí (sin necesidad de entrar al detalle de la diversa estructura de las llamadas cláusulas de apertura) ${ }^{3}$ la cláusula del artículo 1o. de la Constitución. Si a la ampliación extraordinaria del parámetro iusfundamental que de ahí resulta se anuda la puesta en práctica de una difusa trama de control de convencionalidad (y constitucionalidad), el resultado puede ser de difícil gestión y reconducción a la unidad interpretativa que por definición toda Constitución demanda.

3 López Castillo, Antonio, Constitución e integración, Madrid, CEC, 1996; idem, "A propósito de la proyectada articulación de una cláusula europea”, El informe del Consejo de Estado sobre la reforma constitucional, Madrid, CE-CEPC, 2006, pp. 501-532. 
Esta revista forma parte del acervo de la Biblioteca Jurídica Virtual del Instituto de Investigaciones Jurídicas de la UNAM

III. Aproximarse en este contexto a la cuestión del procedimiento de reforma de la Constitución se requiere, más allá de la siempre polémica controversia sobre la práctica efectiva de la reforma constitucional y sobre la eventual modificación, por agravación, del procedimiento de reforma, de algunas precisiones; mediante una complementaria consideración: $a$ ) de constitutione lata (en una doble perspectiva procedimental y doctrinaria), y $b$ ) de constitutione ferenda (en una doble perspectiva procedimental y técnica).

a) De constitutione lata. Se plantea la cuestión de modificar el procedimiento de reforma, al efecto de superar su instrumentalización política, puede tener como finalidad, evitar que se produzca una posible reforma del procedimiento en fraude de Constitución, es decir, para simplificar y desagravar el procedimiento, aun si no se confundiera con el procedimiento legislativo. Pero podría pretender, en contra, un mayor agravamiento del procedimiento (mediante incremento de las exigencias parlamentarias o/y suma de ratificación popular) al efecto de petrificar sus contenidos o, al menos, de dificultar una práctica de reforma que se estima excesiva y desproporcionada, si no incongruente con las ya referidas exigencias sustantivas y estructurales de la Constitución de nuestro tiempo.

Se trata, en suma, de clarificar la relación que la cuestión de la articulación de uno u otro procedimiento de reforma constitucional guarda con la consideración de su sentido y alcance como instrumento de configuración de la realidad política, social y económica de base, con la salvaguarda o no de determinados contenidos, ya sea por la particular exigencia de procedimiento, porque declarada o implícitamente se tengan por intangibles (dicho sea esto, sin perjuicio de la futilidad de distinciones semejantes ante un hipotético cambio de Constitución, en cuya virtud se viera orillada esa doble exigencia de legitimación, de origen y de ejercicio, que caracteriza el constitucionalismo contemporáneo).

Pues bien, de la incesante práctica de reforma constitucional resulta, al parecer, una incuestionable hipertrofia, mediante sucesivo impulso presidencial y partidario, que en la medida en que pretende anclar y potenciar determinadas políticas, en sus diversas facetas competenciales e institucionales, tendrían como consecuencia una agregación, cuando no inconsecuente o incursa en flagrante contradicción, difícilmente reconducible a la unidad que como cabeza del ordenamiento en su conjunto, reclama para sí la Constitución (normativa). 
Esta revista forma parte del acervo de la Biblioteca Jurídica Virtual del Instituto de Investigaciones Jurídicas de la UNAM

b) De constitutione ferenda. Para dar con una salida constitucional practicable ante una situación de (semejante) instrumentalidad partidaria del instituto de la reforma constitucional, puede pensarse, de modo gradual, de menor a mayor exigencia constitucional.

De nulo coste constitucional, bien que no exento de extrema dificultad política, atendida la práctica más reciente sería la solución de compromiso consistente en la determinación política de proceder a desarrollar y regular las previsiones constitucionales, mediante ley, antes que abundar en la inercia de inserción en el texto constitucional de detallados y pormenorizados contenidos típicos de la ley en otros ordenamientos constitucionales de referencia (un auxilio doctrinal al efecto de mostrar esa evidencia a la Presidencia y al Parlamento acaso pudieran resultar de utilidad al efecto de contener la pulsión reformista que parece recorrer el espectro político de la República).

De escaso coste político podría resultar una propuesta refundición a través una doble pero confluente tarea de clarificación y simplificación del vigente texto constitucional. El apoyo técnico preciso podría brindarse en sede académica y por la asesoría de institutos de investigación de acreditada trayectoria, como es el caso del Instituto de Investigaciones Jurídicas, quien bien acredita la organización de esta jornada de estudio. Y la intervención ulterior de las fuerzas políticas mediante la correspondiente votación del texto resultante, aportaría la legitimación necesaria.

De mayor coste político resultaría, sin duda, la alternativa de intervención más intensa: la de reforma radical o renovación del pacto constitucional. A la dificultad política manifiesta, acaso compensable por la renovada legitimación de una Constitución que tanto como la dimensión normativa acredita una faceta simbólico-integrativa no despreciable en una comunidad de plural base y creciente complejidad institucional. Y aun cabe imaginar una hipótesis de ruptura tendente a la apertura de un proceso constituyente a efecto de trazar una línea de cesura con el orden constituido.

Ahora bien, tanto en un caso (reforma integral del texto constitucional vigente) como en el otro (adopción de una nueva Constitución), la relación coste político-beneficio constitucional está por calcular. Y esa es, en consecuencia, una tarea previa a la de plantear reformas o al cambio del texto constitucional vigente.

Quiere decir que antes que dichas propuestas tendentes a la modificación del artículo 135 de la vigente Constitución Política de los Estados Unidos Mexicanos, por más que puedan llegar a entenderse, quizá es aconsejable 
Esta revista forma parte del acervo de la Biblioteca Jurídica Virtual del Instituto de Investigaciones Jurídicas de la UNAM

comenzar a plantear sistemática y razonadamente las inconsecuencias e incongruencias resultantes de la incesante agregación reformista.

Esa tarea es la que en mi modesta opinión cumple abordar en esta hora del constitucionalismo mexicano. Poner en claro que no hay orden constitucional que se estime sin un amplio y consecuente desarrollo legislativo de la Constitución; como no hay una interpretación unitaria factible sin una ordenación de criterios y un adecuado sistema de control al efecto de sentar los estándares constitucionales, propios y estandarizados comunes; como no hay una Constitución operativa sin un aseguramiento de la debida concatenación entre participación democrática y sujeción a control de cualesquiera manifestaciones del poder público, etcétera.

Al efecto, resultaría de la mayor importancia un esfuerzo por profundizar en la actualización de los estudios sobre la Constitución mexicana. Que la doctrina más competente, de la que se cuentan aquí hoy algunos representantes, se empeñe en hacer su labor, si no lejos, al margen, de las pulsiones partidarias, me parece una exigencia preliminar al debate fundado del que la sociedad mexicana pueda servirse.

Que los cien años de la venerada Constitución de 1917, resulten una ocasión para la vivificación del debate constitucional es evidente. Éxito, pues, en la tarea a la que como miembros de la comunidad iberoamericana de constitucionalistas, nosotros nos sumamos, si no estando presentes, desde ultramar. 